\title{
Boost Converter based on Photovoltaic Energy System
}

\author{
Priyabrata Pattanaik
}

\begin{abstract}
The study of the PV system are growing because of large, protected, important, exhaustible and available resource for the future energy supply. The solar output power is dependent on the intensity of the solar cell temperature and radiation of the solar cells. Though PV power generation system implements an efficient utilization of the solar energy, but the conversion energy of the solar cell is very low. Therefore, MPPT is employed in the $P V$ system to make the most of the result as an output power, regardless of the power, temperature \& irradiation circumstances \& of load electrical characteristics. In this work the step up converter is utilized to control the PV power using MPPT control mechanism. The PV module is examined by means of SIMULINK software. The simulation result shows that the proposed MPPT control can be avoided. Tracking deviation and improved result performance in both dynamic state and response can be achieved.
\end{abstract}

Keywords- Photovoltaic system (PV system), solar cell, DC-DC converter, boost converter, MPPT, Perturb and Observe method.

\section{INTRODUCTION}

According to the data, as the population is increasing continuously everyday an electrical power requirement is also improving[1]. The extension of generating power from solar energy. Photovoltaic panel (PV) or solar panel is the key element for electrical energy production. Photovoltaic sources are being used for all the works from small battery charger to the satellite source. The PV is a green, less maintained and pollution free and it does not create any noise pollution also.

As the PV module associated with the load, an operational rarely attains its extreme value. Thus the essential part by the photovoltaic system is "maximum power point tracking (MPPT)". To match the voltage requirement and the supply efficiently to the load, voltage converter is introduced in the system[2]. To acquire the extreme output the MPPT is employed for extracting extreme power through solar PV modules and to transfer the power to attached load. Maximum power can be transferred from solar cell PV module to the connected load by using DC/DC converter (step down/step up). Module and load interference is provided by the DC/DC converter.

MPPT employed in the PV system to make the most of the photovoltaic array's output power, regardless to the radiation an temperature situations and also of a load characteristics of the electrical for "DC-DC converter" like "buck-converter and boostconverter" and "buck-boost configurations"[3].

Many techniques are being used widely in the world for the MPP tracking. The observe and perturb method and the incremental conductance method, and other variants of those techniques are also being used for the implementation of the MPP system, it deviates the observed method, thus oscillates close to a power point maximum (MPP) in the atmospheric conditions which change slowly or kept constant[4].

\section{BLOCK DIAGRAM OF CIRCUIT}

The usual block diagram shown in the figure 1. System comprising of "solar panel (PV)", "DC-DC converter", "MPPT controller", desired load. Voltage \& current instruments are deployed to find the starting voltage \& current. The input of MPPT controller is both current and voltage, and an output by the MPPT block is employed as DC-DC converter which may be voltage parameters duty cycle[5].

The "maximum power point" voltage is maintained by installed DC-DC converter, by changing the duty cycle by DC-DC converters. Normally, boost, buck and buck-boost configuration is connected between the load and solar panel.

DC-DC converter as connected concerning PV panel \& the attached load. MPPT algorithms helps to proceed the current and voltage values, which gives the gating signal to the Boost converter[6].

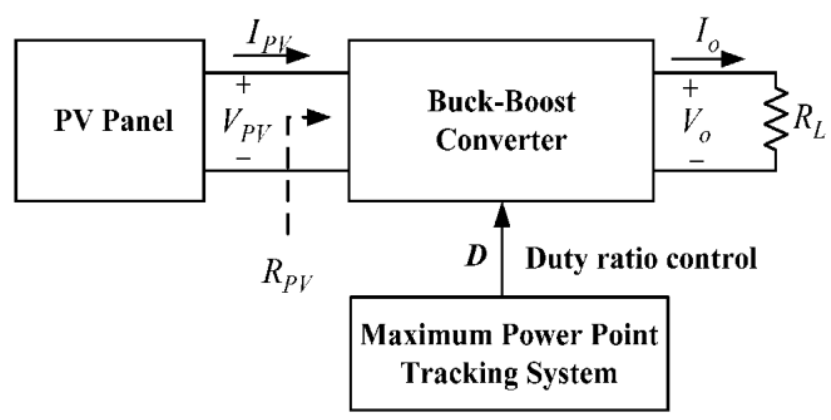

Figure 1. Block Diagram

\section{MODELLING OF THE PV CELL}

Solar cell (PV cell) directly converts sunlight into the DC power. The energy from the sun is generated by the PV cell. hen sunlight falls on the solar panel the solar energy consumed is then renewed to electrical energy. The figure elow shows the system configuration[7].

Revised Manuscript Received on September 10, 2019.

Priyabrata Pattanaik, Dept. of Electronics and Communication Engg, Siksha 'O' Anusandhan Deemed to be University, Odisha, India.

(Email: priyabratapattanaik@soa.ac.in) 


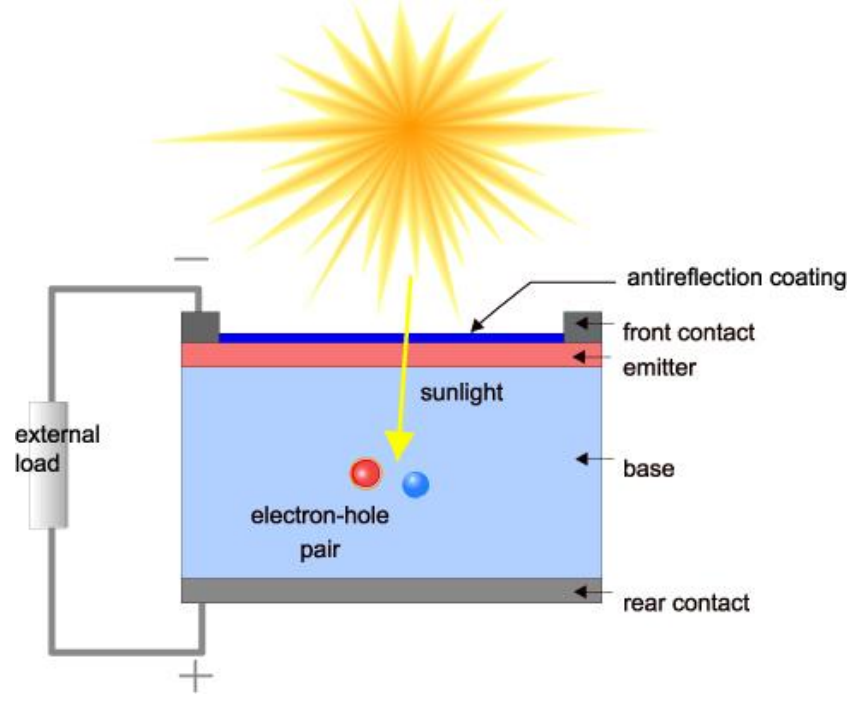

Figure 2. PV Cell

The PV array is a combination of parallel and series combination of solar cells. The particular array generates a power directly with the help of the solar and it changes by the contingent on the irradiances and the temperature[8].

Figure 3. Shows alike circuit diagram by the prototypical that consist of the photo current, the diode, \& a parallel resistors uttering "leakage current", and the series resistor defining the current flow interior resistance of that current flows to the circuit[9].

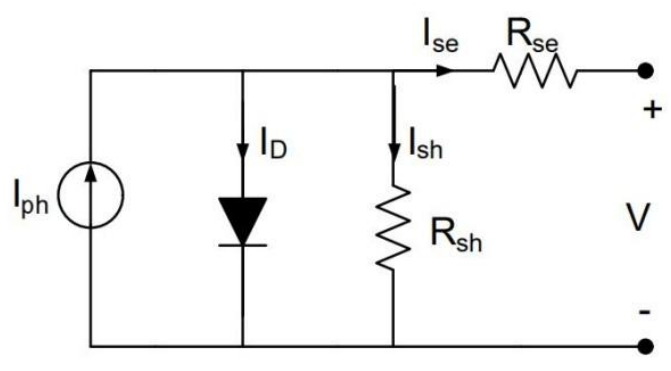

Figure 3. PV cell equivalent circuit diagram

A semiconductor confluence used in a "solar cell" is a p-n junction. A DC power is generated when bare to the light. The current generated fluctuates with the solar irradiances linearly[8].

The solar cell "I-V characteristics" could be resolute according to the succeeding equation. The current through the diode is produced by:

$$
\mathrm{I}_{\mathrm{D}}=\mathrm{I}_{0}\left[\exp \left(\mathrm{q}\left(\mathrm{V}+\mathrm{IR}_{\mathrm{se}}\right) / \mathrm{KT}\right)-1\right]
$$

While, the solar cell output current:

$$
\begin{gathered}
I_{\mathrm{se}}=\mathrm{I}_{\mathrm{ph}}-\mathrm{I}_{\mathrm{D}}-\mathrm{I}_{\mathrm{sh}} \\
\mathrm{I}_{\mathrm{se}}=\mathrm{I}_{\mathrm{ph}}-\mathrm{I}_{0}\left[\exp \left(\mathrm{q} \frac{\mathrm{V}+\mathrm{IR}_{\mathrm{se}}}{\mathrm{KT}}\right)-1\right]-\left(\frac{\mathrm{V}+\mathrm{IR}_{\mathrm{se}}}{\mathrm{R}_{\mathrm{sh}}}\right)
\end{gathered}
$$

Where,
$\mathrm{I}_{\mathrm{se}}$ : Cell current (A).

$\mathrm{I}_{\mathrm{ph}}$ : Light Generated Current (A).

$\mathrm{I}_{0}$ : Diode Saturation Current.

$\mathrm{Q}$ : Charge of Electron $=1.6 \times 10-19$ (Coul).

$\mathrm{K}$ : Boltzmann Constant $(\mathrm{J} / \mathrm{K})$

V : Cell Output Voltage (V)

$\mathrm{R}_{\mathrm{se}}, \mathrm{R}_{\mathrm{sh}}$ : Cell Series and Shunt Resistance (Ohms).

\section{ROLE OF THE MPPT IN PV SYSTEM}

The "solar panel" efficiency is precisely lesser. So to improvise its efficiency that results matching of the source to a load appropriately there must be a proper method applied. MPPT method is a method for the same. We can obtain maximum power point tracking from a varying source using this technique[10]. The "I-V curve" is nonlinear in the PV system, finds difficulties in powering to the attached load. This is performed by employing a boost configuration converter having a variable duty cycle by means of MPPT protocol.

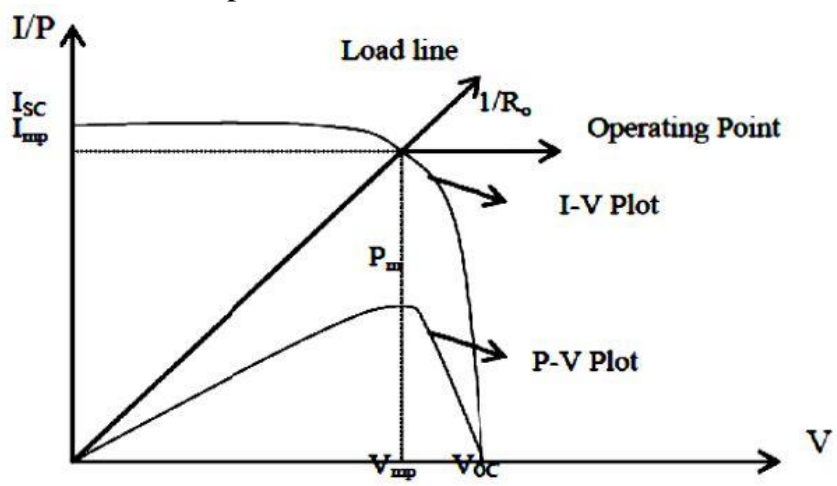

Figure 4 Maximum power point output

The point tracked where $I_{m p} \& V_{m p}$ bump into the extreme power point as shown in figure 4 . This point demonstrates the thorough going power existing by the PV cell. As the "load line" crosses the very point accurately, then after the extreme power is being transmitted to the attached load[10].

\section{MPPT TECHNIQUES}

There are so many methods applied for maximum point tracking as shown below

- Perturb and Observe method

- Incremental conductance method

- Constant voltage method

- Constant current method

\section{PERTURB AND OBSERVE MEHTOD}

The appellation itself suggests a technique is on the basis of statement of an array yields power \& the perturbation (addition and decrement) of the power is on the basis of rise by voltage and current. Minor perturbation has been 
familiarized in this system. This results in the change in the power solar modules. As a power grows upon the direction of the perturbation, a system follow that particular direction. As the top point is attained that very power on that instant decrease and henceforth that perturbation is reversed. The oscillation revolve all over the place to highest point as the steady state is attained. Said perturbation scope kept smaller so as to retain the power distinction low[11].

The small increment $\Delta \mathrm{V}$ is in the $\mathrm{PV}$ system of the operating system is perturbed, which results change in $\Delta \mathrm{P}$. If the $\Delta \mathrm{P}$ will be positive, the same directional operating voltage needs to be perturbed for the increment. On the other hand, as the $\Delta \mathrm{P}$ will be -ve, the obtained operatingpoint system should move left to a MPP and said direction of functioning voltages essentially be opposite to the direction of increment.

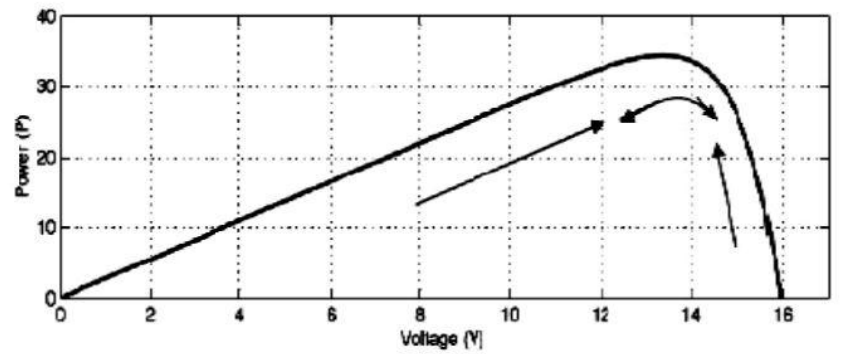

Figure 5. PV characteristics for P\&O method

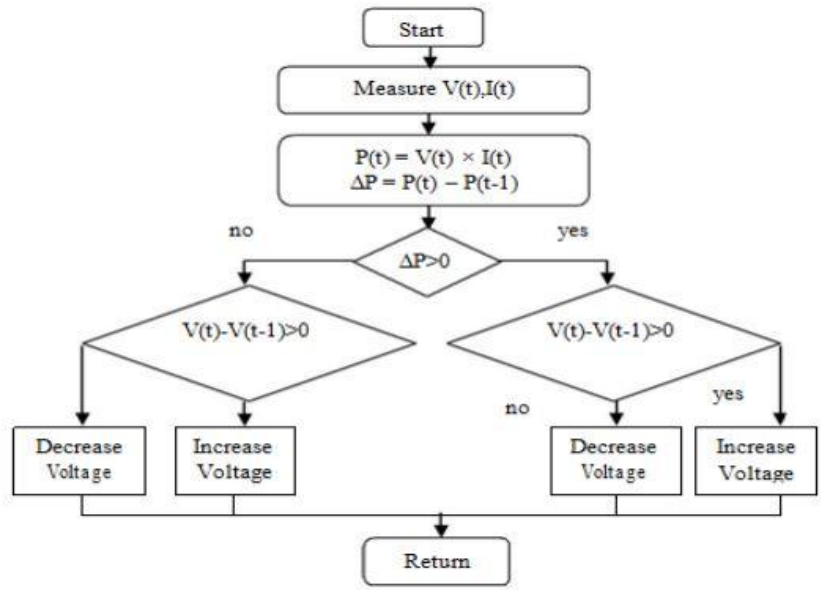

Figure 6. P\&O and observation algorithm flow chart

\section{BOOST CONVERTER AND ITS OPERATION}

As shown in the figure a stage awake or the "PWM boost converter". That one comprises of "DC input voltage Vg", "L (boost inductor)", "S (controlled switch)", and "D (diode)", "C (filter capacitor)" and "R (load resistance)". As long as the switch $\mathrm{S}$ is in on state, the boost converter current upsurges linearly that very time the diode $\mathrm{D}$ will be off. As the switch $\mathrm{S}$ be off, the stored power of that inductor will be unconstrained by means of the diode to an output "RC circuit"[12].

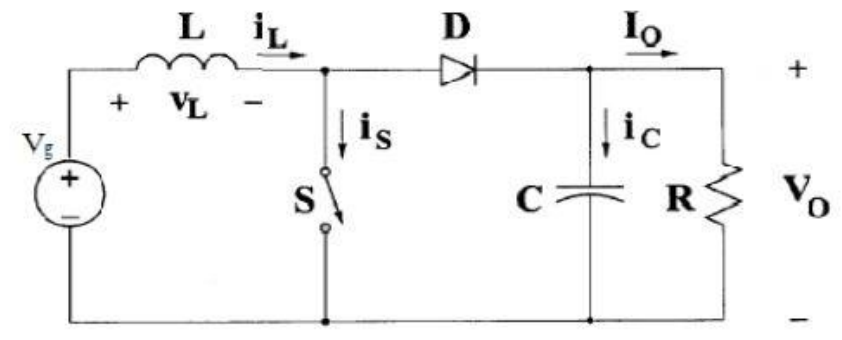

Figure 7. Boost Converter's circuit diagram

\section{MODE 1: CHARGING MODE}

Inductor gets charged through the battery as soon as switch is OFF and it stocks the "Energy". Said inductor current exponentially rises in the charging mode but for simplification in calculation we undertake the discharging $\&$ the charging of said inductor in linearly changing. The diode restricts the forward current for maintaining the "load current constant" that is delivered through the discharging capacitor.

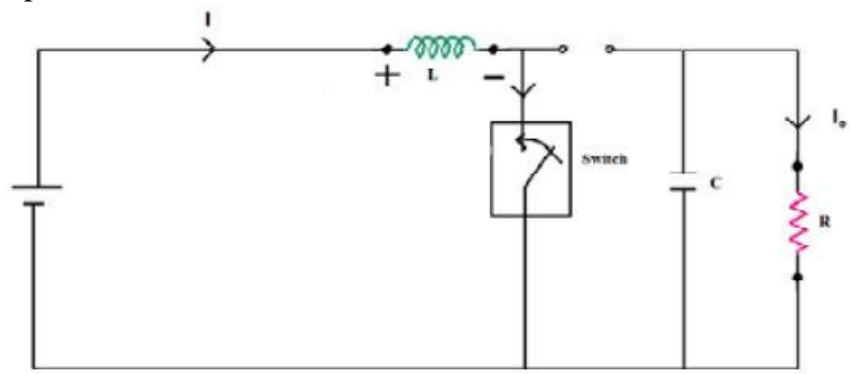

Figure 8. Mode 1 operation of Boost Converter.

\section{MODE 2: DISCHARGING MODE}

In mode 2, the diode become short circuited as the switch gets open. The stored energy in said inductor discharging by means of the polarity contrary to the charging polarity. The "load current" leftovers constant during the course of the whole procedure. The boost converter waveform are shown below.

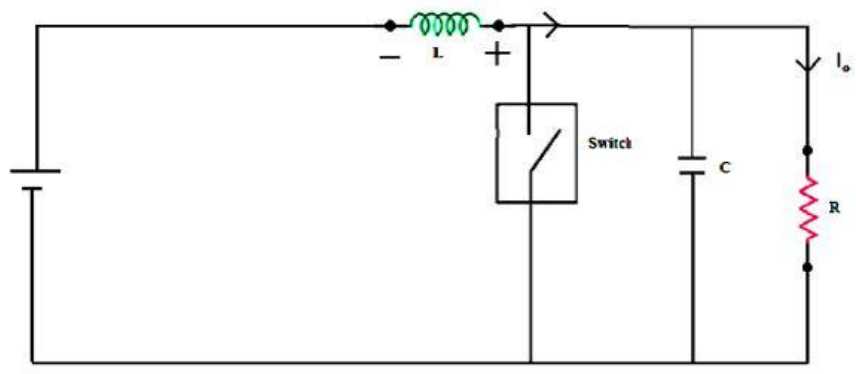

Figure 9. Mode 2 boost converter's operations

\section{SIMULATION USING PV PANEL}

"Equivalent circuit of PV cell" shown in the figure 3, the current at the load is given by the equation 
$\mathrm{I}_{\mathrm{se}}=\mathrm{I}_{\mathrm{ph}}-\mathrm{I}_{0}\left[\exp \left(\mathrm{q} \frac{\mathrm{V}+\mathrm{IR}_{\mathrm{se}}}{\mathrm{KT}}\right)-1\right]-\left(\frac{\mathrm{V}+\mathrm{IR}_{\mathrm{se}}}{\mathrm{R}_{\mathrm{sh}}}\right)$

environmental parameters as the "solar radiation" \& the "temperature".

The PV cell complete physical behaviour in relation with Iph, Ise, Rse and Rsh from the other hand and with the

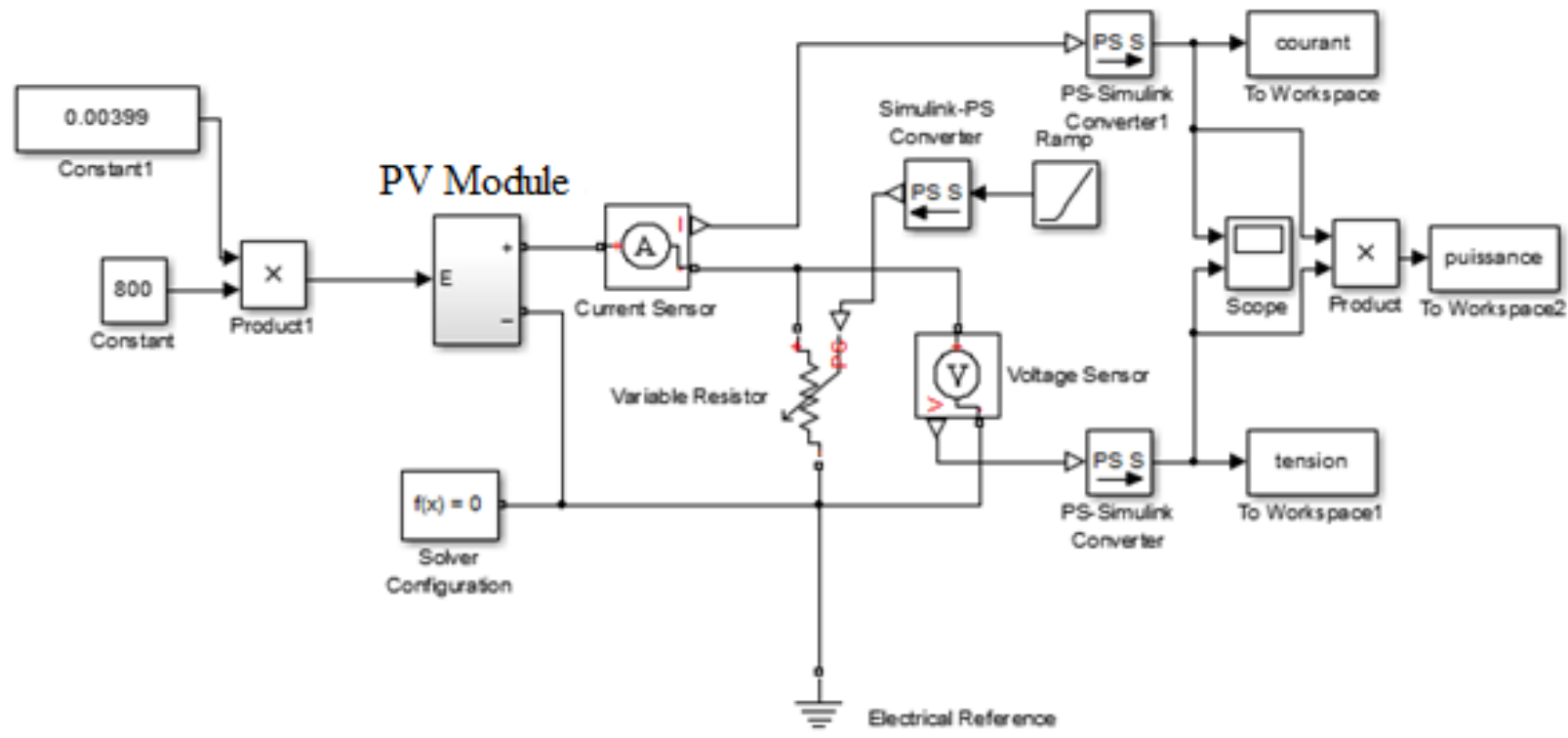

Figure 10. Simulation by PV module

On the basis of the equation, the MATLAB/SIMULINK model of the Figure was developed. For a given radiations, temperatures, Rsh and Rs, the I-V \& P-V curves are prepared.

\section{PV CELL SIMULATION RESULT}

I-V characteristics:

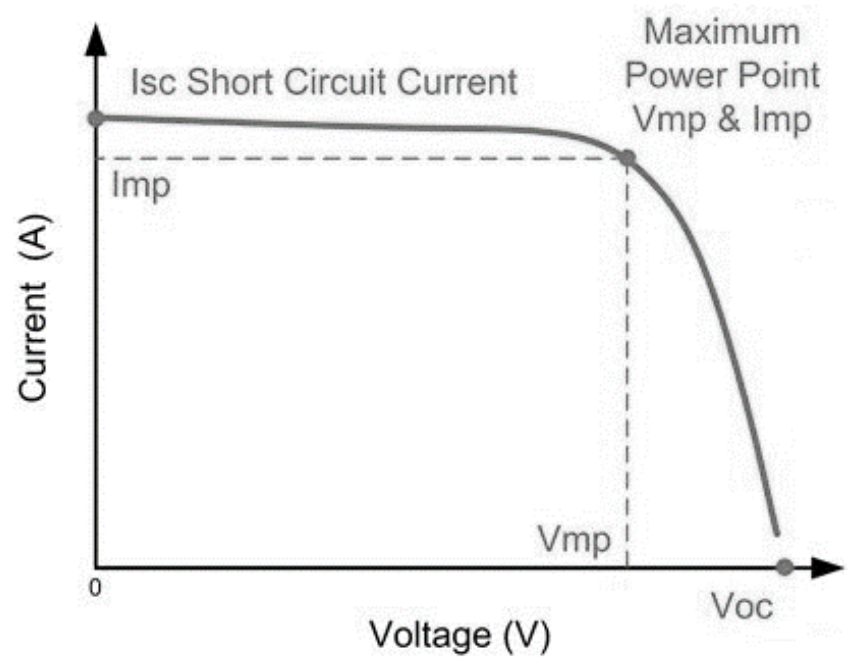

Figure 11. PV panel I-V characteristics

PV module I-V characteristics is as shown in the figure 11. The current $\mathrm{I}$ is plotted in $\mathrm{Y}$-axis and voltage $\mathrm{V}$ is plotted in $\mathrm{X}$-axis, the panel will provide maximum output power at a maximum point in MPP. The value of voltage and current will change as the sunlight is not constant all day.

\section{$>\quad P V$ panel $P$-V characteristics}

The panel "P-V characteristics" is demonstrated in the figure 12. The power is plotted in y-axis and the voltage $\mathrm{V}$ is plotted in the $\mathrm{x}$-axis where the panel is providing the extreme power output. Voltage \& current standards changes all along the day as the sunlight is variable, which results change in the output power.

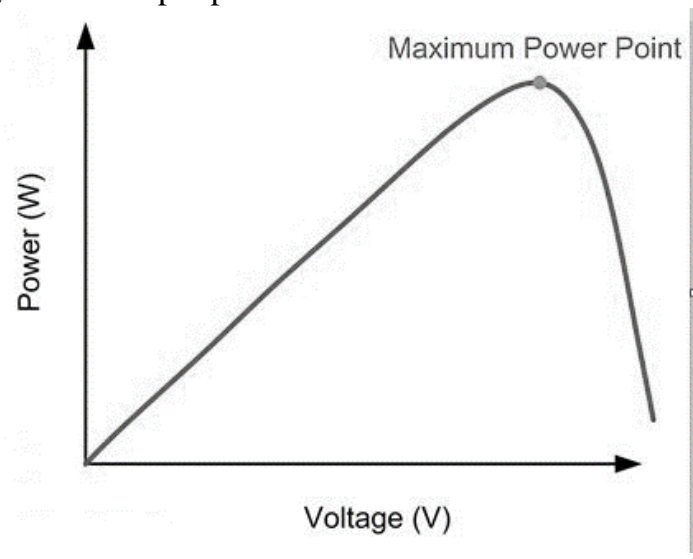

Figure 12. P-V characteristics of the PV panel

\section{SIMULATION OF THE BOOST CONVERTER}

Boost converter, a DC to DC converter with the greater output voltage than the input voltage. The aim of this converter is to attain the maximum output as much as we can do from the DC. The circuit shown in figure 11. Is a

Published By: 


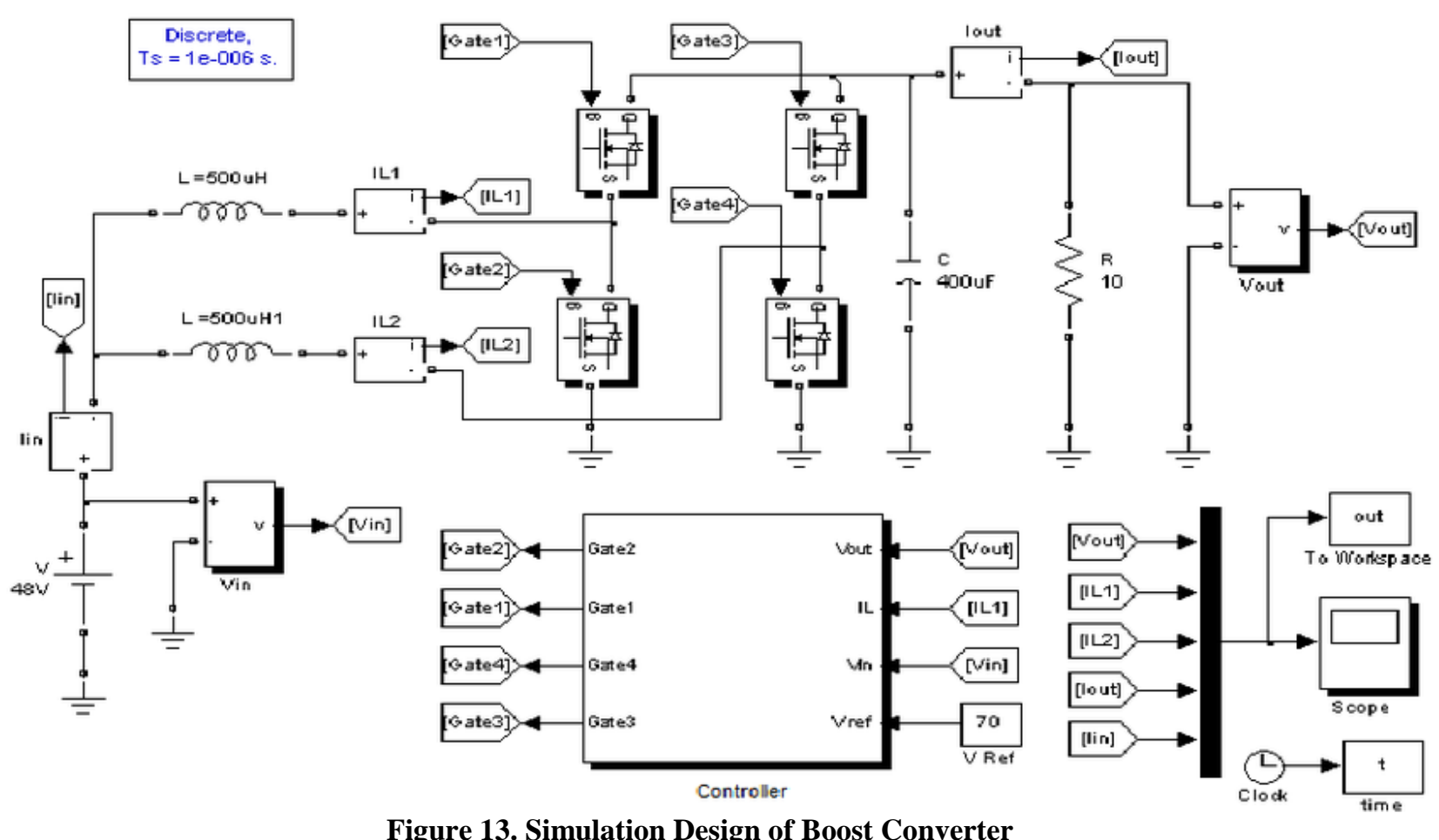

The parameters values $\mathrm{Vs}=15 \mathrm{~V}, \mathrm{R}_{\text {load }}=400, \mathrm{C} 1=\mathrm{C} 2=47 \mathrm{e}$ ${ }^{6} \mathrm{~F}, \mathrm{C} 3=220 \mathrm{e}^{-6} \mathrm{~F}, \mathrm{~L}=1 \mathrm{e}^{-3} \mathrm{H}$ ohms, $\mathrm{V}{ }_{\mathrm{o}}=56 \mathrm{~V}$. Simulation of "boost converter" consist of "DC input voltage source", MOSFET button, 2 inductor, 3capacitor and 3 diode. To verify the result output we connected the scope and to give the pulse we connected the generator and finally, Powergui. This work is proposed to develop DC to DC boost converter. The boost coveter will be then able to boost $15 \mathrm{~V}$ to $(55-56)$ V.

\section{BOOST CONVETER OUTPUT WAVEFORM}

The boost converter output waveform is shown in the figure 15 . On the $y$-axis the output voltage $\mathrm{V}$ is plotted and on the $\mathrm{x}$-axis time $\mathrm{t}$ is plotted. The input provided at said boost converter is $15 \mathrm{~V} \&$ said output voltage as approximately $56 \mathrm{~V}$.

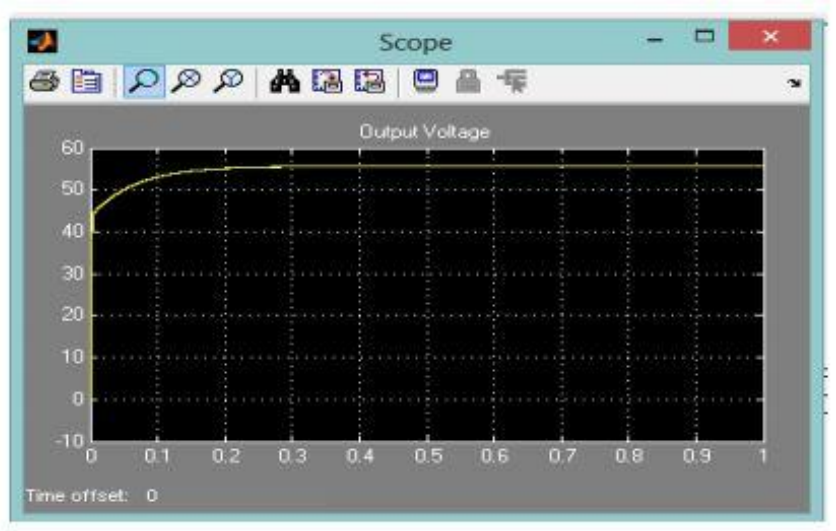

Figure 14. Boost converter output waveform

\section{CONCLUSION}

The work architect is performed in "SIMULINK software", and study and analysis of the output characteristics for a PV array is performed. Mainly "P\&O MPPT algorithm" is deployed to result the maximize power point that aid in stepping down an "array voltage" for maximising the operating point of said voltage. So, the "MPPT procedure boost converter solar array" is activated irrespective of the extreme power point sun irradiance.

\section{REFRENCES}

1. M. H. Taghvaee, M. A. M. Radzi, S. M. Moosavain, H. Hizam, and M. Hamiruce Marhaban, "A current and future study on non-isolated DC-DC converters for photovoltaic applications," Renewable and Sustainable Energy Reviews. 2013.

2. P. Goli and W. Shireen, "PV powered smart charging station for PHEVs," Renew. Energy, 2014.

3. O. Guenounou, B. Dahhou, and F. Chabour, "Adaptive fuzzy controller based MPPT for photovoltaic systems," Energy Convers. Manag., 2014.

4. "Photovoltaic Power Control Using MPPT and Boost Converter," Balk. J. Electr. Comput. Eng., 2015.

5. H. Fathabadi, "Novel high efficiency DC/DC boost converter for using in photovoltaic systems," Sol. Energy, 2016.

6. F. Nejabatkhah, S. Danyali, S. H. Hosseini, M. Sabahi, and S. M. Niapour, "Modeling and control of a new three-input dc-dc boost converter for hybrid PV/FC/battery power system," IEEE Trans. Power Electron., 2012.

7. R. K. Kharb, S. L. Shimi, S. Chatterji, and M. F. Ansari, "Modeling of solar PV module and maximum power point tracking using ANFIS," Renewable and Sustainable Energy Reviews. 2014.

8. R. I. Putri, S. Wibowo, and M. Rifa'i, "Maximum power point tracking for photovoltaic using incremental conductance method," in Energy Procedia, 2015.

9. R. Ayop and C. W. Tan, "Design of boost converter based on maximum power point resistance for 
photovoltaic applications," Sol. Energy, 2018.

10. R. Reshma Gopi and S. Sreejith, "Converter topologies in photovoltaic applications - A review," Renewable and Sustainable Energy Reviews. 2018.

11. D. K. Sharma and G. Purohit, "Advanced perturbation and observation $(\mathrm{P} \& \mathrm{O})$ based maximum power point tracking (MPPT) of a solar photo-voltaic system," in India International Conference on Power Electronics, IICPE, 2012.

12. D. J. S. Newlin, R. Ramalakshmi, and S. Rajasekaran, "A performance comparison of interleaved boost converter and conventional boost converter for renewable energy application," in 2013 International Conference on Green High Performance Computing, ICGHPC 2013, 2013. 